\title{
BIOLOGI REPRODUKSI IKAN CAKALANG (Katsuwonus pelamis) DI SAMUDERA HINDIA BAGIAN TIMUR
}

\section{REPRODUCTIVE BIOLOGY OF SKIPJACK TUNA (Katsuwonus pelamis) IN EASTERN INDIAN OCEAN}

\author{
Irwan Jatmiko, Hety Hartaty dan Andi Bahtiar \\ Loka Penelitian Perikanan Tuna, Denpasar \\ Teregistrasi I tanggal: 10 September 2014; Diterima setelah perbaikan tanggal: 30 Juli 2015; \\ Disetujui terbit tanggal: 05 Agustus 2015 \\ e-mail:irwan.jatmiko@gmail.com
}

\begin{abstract}
ABSTRAK
Cakalang (Katsuwonus pelamis) adalah salah satu hasil tangkapan penting bagi nelayan di Samudera Hindia. Penelitian ini bertujuan untuk mengetahui perkembangan gonad dan panjang pertama kali matang gonad cakalang di Samudera Hindia. Sampel cakalang dikumpulkan dari beberapa tempat di Pantai Selatan Jawa yaitu: Palabuhanratu, Cilacap, Pacitan, Sendang Biru, Kedonganan, Tanjung Luar, Labuhan Lombok dan Oeba dari bulan April 2012 sampai November 2013. Panjang cagak dari 136 sampel berkisar antara 35-68 cm. Tingkat kematangan gonad (TKG) diamati secara histologi dan analisis Gonadosomatic index (GSI). Hasil penelitian ini menunjukkan bahwa TKG cakalang didominasi oleh TKG IV sebesar 43\%, diikuti dengan TKG III (21\%), TKG I (17\%), TKG II (16\%) dan TKG V (2\%). Panjang pertama kali matang gonad terjadi pada ukuran $42,9 \mathrm{~cm}$.
\end{abstract}

KATA KUNCI: Cakalang, tingkat kematangan gonad, GSI, Samudera Hindia Bagian Timur

\begin{abstract}
Skipjack tuna (Katsuwonus pelamis) is the one of the important catch for fishermen in the Indian Ocean. The objectives of this research are to investigate gonad maturity and length at first maturity for female cakalang in Indian Ocean. Skipjack tuna were sampled from several places in South Coast of Java i.e.: Palabuhanratu, Cilacap, Pacitan, Sendang Biru, Kedonganan, Tanjung Luar, Labuhan Lombok and Oeba from April 2012 to November 2013. Fork length of the sampled 136 fish ranged from 35 to $68 \mathrm{~cm}$. Maturity stage (TKG) investigate using histological analysis and Gonadosomatic index (GSI) calculation. The results showed that maturity stage of skipjacktuna dominated by TKG IV with 43\%, followed by TKG III (21\%), TKG I(17\%), TKG II (16\%) dan TKG V (2\%). Length at first maturity occurred at $42.9 \mathrm{~cm}$.
\end{abstract}

KEYWORDS: Skipjack tuna, maturity stage, GSI, Eastern Indian Ocean

\section{PENDAHULUAN}

Produksi cakalang di Indonesia merupakan yang terbesar diantara kelompok tuna yang lain. Hasil tangkapan tuna mencapai 933.815 ton dari tahun 2001 hingga 2010. Dari total tangkapan tuna tersebut, produksi cakalang merupakan yang tertinggi mencapai $52 \%$, diikuti oleh madidihang (20\%), tuna mata besar (15\%), albakor (11\%) dan southern bluefin tuna (1\%) (FAO, 2012).

Cakalang merupakan highly migratory species yang distribusinya dari perairan tropis hingga perairan subtropis (Collette dan Nauen, 1983). Spesies ini melakukan beberapa kali pemijahan pada daerah dimana suhu permukaan laut lebih tinggi dari $24^{\circ} \mathrm{C}$ (Matsumoto et al., 1984). Penelitian tentang tingkat kematangan gonad menggunakan analisis histologi masih sangat kurang di Indonesia.
Salah satu aspek untuk mendukung upaya pengelolaan sumber daya ikan adalah pengetahuan dasar mengenai aspek biologi reproduksi. Penelitian tentang biologi reproduksi ikan dapat memberi data dan informasi penting mengenai frekuensi pemijahan, keberhasilan pemijahan, lama pemijahan dan ukuran ikan ketika pertama kali mencapai kematangan gonad (Mardlijah \& Patria, 2012). Penentuan tingkat kematangan gonad selain menggambarkan siklus reproduksi, juga berkaitan dengan pendugaan umur atau ukuran ikan mencapai matang gonad dan waktu pemijahan (Abidin, 1986). Pengamatan melalui analisis histologi banyak digunakan untuk mengetahui biologi reproduksi pada ikan tuna dan metode ini memberikan hasil yang akurat tentang status reproduksi ikan tuna (Schaefer, 2001).

Penelitian ini bertujuan untuk mengetahui aspek biologi reproduksi cakalang yaitu: tingkat kematangan gonad, dugaan musim pemijahan dan panjang pertama kali matang $\operatorname{gonad}(\mathrm{Lm})$. 


\section{METODE}

Sampel gonad cakalang diperoleh dari hasil tangkapan armada pancing ulur dan tonda yang beroperasi di Samudera Hindia Bagian Timur di selatan Jawa.Pengambilan sampel gonad dilakukan di beberapa pelabuhan ikan di Pantai Selatan Jawa, yaitu: Palabuhanratu, Cilacap, Pacitan, Sendang Biru, Kedonganan, Tanjung Luar, Labuhan Lombok dan Oeba (Gambar 1). Pengambilan sampel dilakukan setiap bulan selama 13 bulan yaitu mulai dari bulan April-Agustus 2012, bulan Maret 2013 dan bulan Mei-November 2013. Sampel gonad diambil dan diawetkan ke dalam larutan alkohol 90\% kemudian dianalisis di laboratorium histologi Loka Penelitian Perikanan Tuna Benoa. Pengumpulan data lainnya meliputi ukuran panjang cagak dan berat ikan dari keseluruhan sampel gonad yang diambil. Tingkat kematangan gonad diamati secara histologi dan analisis Gonadosomatic index (GSI). Tingkat kematangan gonad cakalang dilakukan secara histologi mengikuti kriteria perkembangan oosit oleh Davis et al. (1996) yang membagi tingkat kematangan gonad betina menjadi 5 tingkat (Lampiran 1).

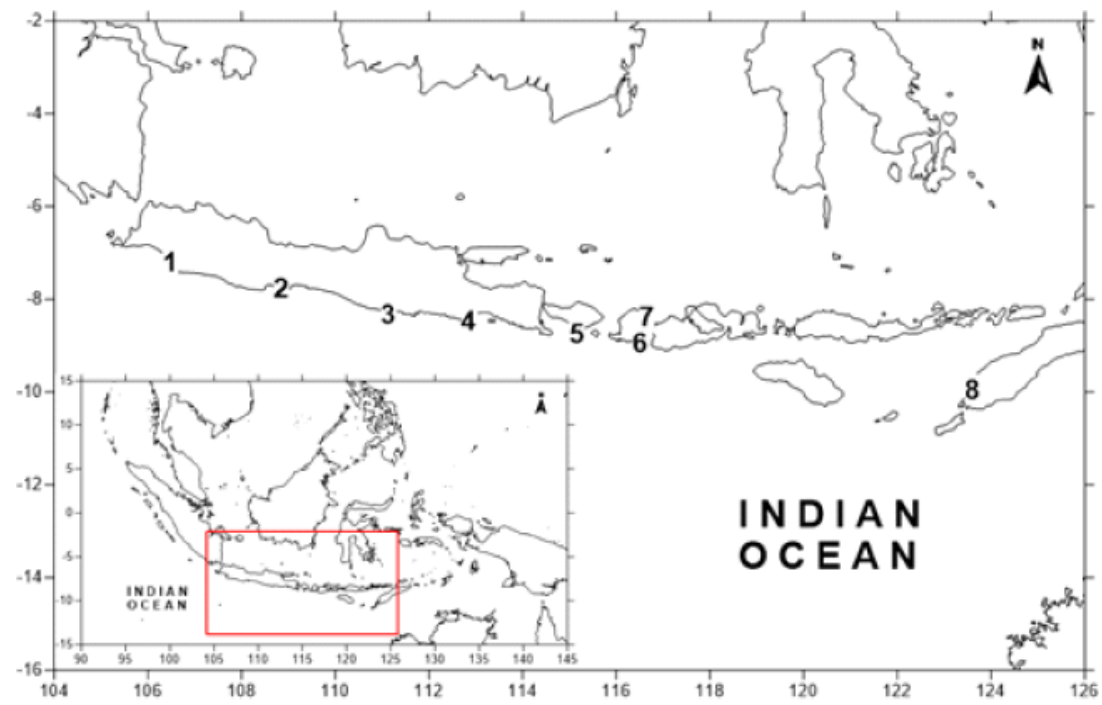

Gambar 1. Lokasi pengambilan sampel gonad ikan cakalang di Palabuhanratu (1), Cilacap (2), Pacitan (3), Sendang Biru (4), Kedonganan (5), Tanjung Luar (6), Labuhan Lombok (7) dan Oeba (8).

Figure 1. Gonad of skipjack sampling sites in Palabuhanratu (1), Cilacap (2), Pacitan (3), Sendang Biru (4), Kedonganan (5), Tanjung Luar (6), Labuhan Lombok (7) and Oeba (8).

Tingkat kematangan gonad dianalisis dengan rumus GSI dari Afonso-Dias et al. (2005):

$$
G S I=\frac{G w}{B w} X 100 \%
$$

Keterangan:

$$
\begin{aligned}
& \text { GSI }=\text { Gonadosomatic index } \\
& \mathrm{GW}=\text { berat gonad (gram) } \\
& \mathrm{W}=\text { berat total (gram) }
\end{aligned}
$$

Panjang pertama kali matang gonad (Lm/Length at first maturity) dianalisis dengan metode Spearman - Karber (Udupa,1986):

$$
m=x k+X / 2-\left(X \sum p i\right)
$$

Keterangan:

$\mathrm{m}=$ logaritma ukuran pertama kali matang gonad

$\mathrm{xk}=$ logaritma nilai tengah kelas terakhir dimana terjadi matang gonad $100 \%$
$\mathrm{X}=$ selisih logaritma nilai tengah

$\mathrm{Pi}=$ perbandingan matang gonad tiap kelas panjang

$$
C L=\text { anti } \log \left[m \pm 1.96 \sqrt{x^{2} \Sigma}\left\{\frac{p i \times \mathrm{qi}}{n i-1}\right\}\right.
$$

Keterangan:

$\mathrm{C}=$ Convidence limit (batas atas dan bawah)

$\mathrm{m}=$ panjang ikan pertama kali matang gonad

$\mathrm{ni}=$ jumlah ikan pada kelas panjang ke-i

qi $=1-p i$

\section{HASIL}

Penamatan terhadap 136 ekor cakalang ditemukan bahwa sebaran panjang cagak berkisar antara $35-68 \mathrm{~cm}$ dan didominasi dengan nilai tengah panjang $50 \mathrm{~cm}$ (Gambar 2). 


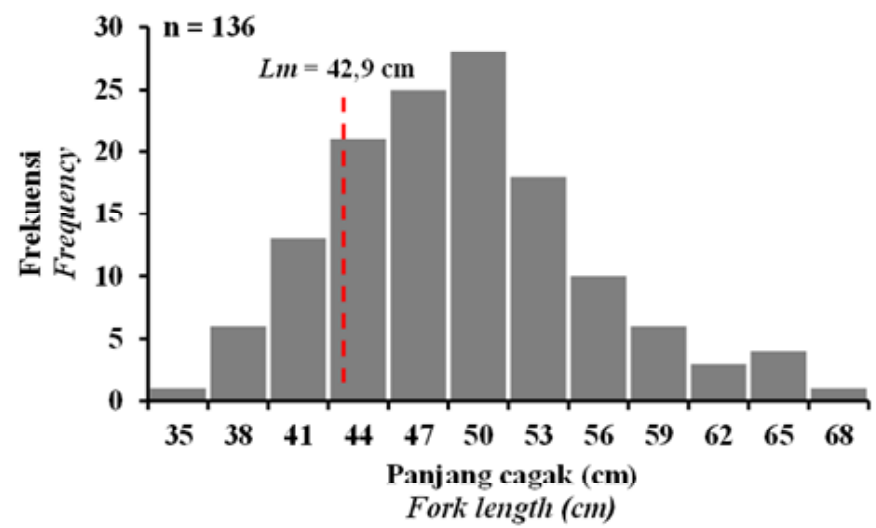

Gambar 2. Frekuensi panjang cakalang (Katsuwonus pelamis) di Samudera Hindia.Panjang cagak merupakan nilai tengah dengan interval $3 \mathrm{~cm}$.

Figure 2. Length frequency of skipjack tuna (Katsuwonus pelamis) in Indian Ocean. Fork length is mid-length with 3 cm intervals.

Pengamatan histologi menunjukkan bahwa gonad cakalang yang tertangkap terjadi pada semua tingkat kematangan gonad (TKG) dari TKG I hingga TKG V.Pada TKG I, perkembangan gonad masih dalam tahap oogenesisyaitu proses pembentukan sel telur (oosit). Sel telur masih berukuran kecil dan inti sel (nucleus) berbentuk bulat atau oval dengan sitoplasma yang lebih tebal. TKG II, oosit mulai berkembang dan memasuki tahap awal vitellogenesisyaitu proses pengendapan kuning telur pada tiap-tiap sel telur. Ukuran diameter oosit meningkat, inti sel kelihatan bertambah besar dan kuning telur tersebar di sekitar oosit dan inti sel.

TKG III, disebut juga advanced yolked stage atau tahap permulaan matang gonad. Pada tahap ini jumlah dan ukuran butiran kuning telur semakin bertambah dan nampak jelas di seluruh area oosit.Butiran minyak (oil droplet) mulai terlihat di dalam sitoplasma, inti sel terkonsentrasi di sentral oosit dan zona radiata melebar. TKG IV, memasuki tahap awal matang gonad ataumaturation. Butiran kuning telur sudah banyak

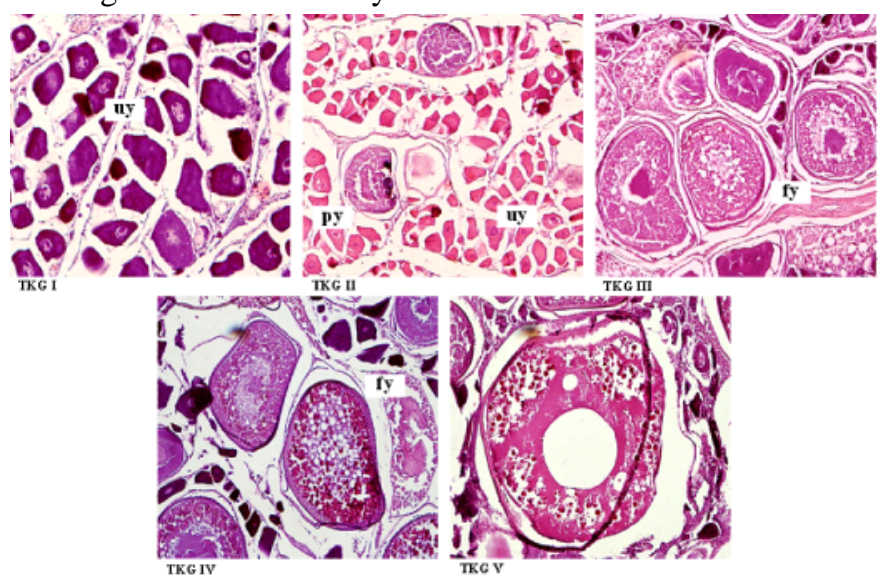

Gambar3. Irisan histologi gonad ikan cakalang dari TKG I hingga TKG V dengan perbesaran 100x.uy $=$ unyolked; py $=$ partially yolked; fy= fully yolked.

Figure 3. Histological section of skipjack tuna gonads from TKG I to TKG V with 100x magnifications. uy = unyolked; py = partially yolked; fy = fully yolked. mencapai fully yolked oocytes, butiran minyak semakin banyak menyebar dari sekitar inti sel sampai ke pinggiran oosit.Inti sel bermigrasi menuju sekeliling oosit dan biasanya tergantikan dengan beberapa butiran minyak. TKG V, merupakan tahap matang akhir atau hydrated stage. Kuning telur tergabung menjadi satu dan tampak seperti noda (Gambar 3).

Dari gambar 4 dapat diketahui bahwa cakalang mengalami matang gonad hampir sepanjang tahun dengan puncaknya terjadi pada bulan Juni dan Juli. Persentase TKG pada masing-masing kelas panjang juga menunjukkan bahwa TKG IV juga mendominasi jika dihubungkan dengan panjang cagak. TKG IV terdapat padanilai tengah kelas panjang lebih dari $41 \mathrm{~cm}$ kecuali pada nilai tengah kelas panjang $62 \mathrm{~cm}$. Selanjutnya, TKG IV juga terdapat secara penuh (100\%) pada nilai tengah kelas panjang $65 \mathrm{~cm}$ dan $68 \mathrm{~cm}$. Selain itu, TKG I dan TKG II terdapat secara penuh pada nilai tengah kelas panjang $35 \mathrm{~cm}$ dan $38 \mathrm{~cm}$ (Gambar 5). 




Gambar 4. Persentase tingkat kematangan gonad (TKG) cakalang.

Figure 4. Percentage of maturity stage for skipjack tuna .

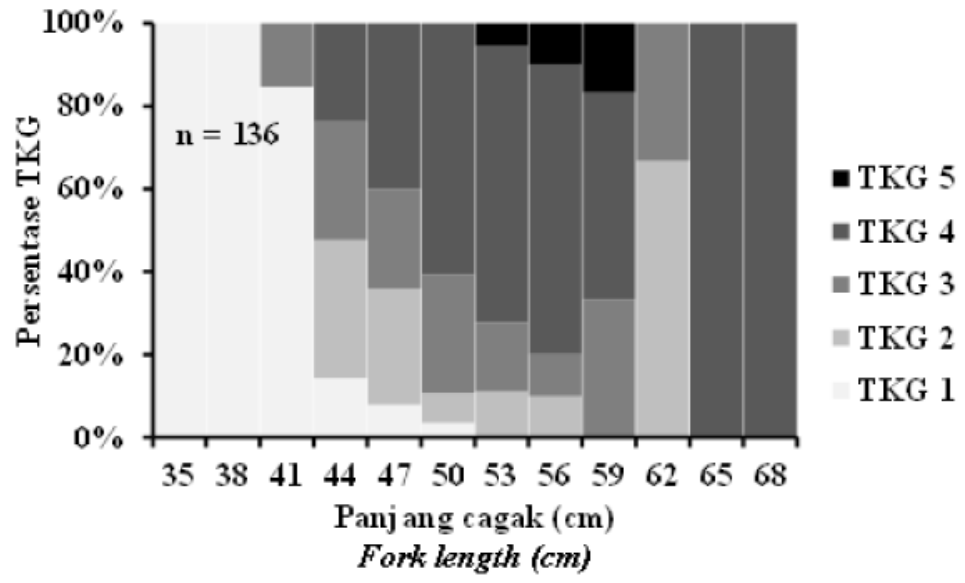

Gambar 5. Tingkat kematangan gonad (TKG) cakalang berdasarkan kelas panjang.Panjang cagak merupakan nilai tengah dengan interval $3 \mathrm{~cm}$.

Figure 5. Maturity stage for skipjack tuna based on length class. Fork length is mid-length with $3 \mathrm{~cm}$ intervals.

Observasi makroskopis terhadap rerata nilai Gonadosomatic index (GSI) cakalang adalah 1,44 (0,71 2,56). Sebaran GSI tiap bulan menunjukkan bahwa GSI tertinggi terjadi pada bulan Oktober 2013, sedangkan terendah terjadi pada bulan Agustus 2012. Dari bulan September 2012 hingga Februari 2013 dan bulan April 2013 tidak ada data karena keterbatasan anggaran penelitian



Gambar 6. Sebaran GSI bulanan cakalang di Samudera Hindia dari bulan April 2012 hingga November 2013.

Figure 6. Monthly GSI distributions of skipjack tuna in Indian Ocean from April 2012 to November 2013. 


\section{BAHASAN}

Cakalang mempunyai sifat pemijahan asynchronous, dimana dalam satu irisan gonad terdapat beberapa ukuran oosit. Keadaan ini seperti yang terjadi pada ikan tuna sirip kuning yang tertangkap di Pelabuhan Benoa - Bali (Andamari et al., 2012; Faizah \& Prisantoso, 2010). Hal ini juga sejalan dengan penelitian yang dilakukan oleh Matsumoto et al. (1984) yang menyatakan bahwa cakalang melakukan pemijahan sepanjang tahun dan telur dikeluarkan secara bertahap dalam waktu yang panjang (partial spawner) (Effendie, 2002).

Secara umum, tingkat kematangan gonad (TKG) cakalang yang tertangkap di Samudera Hindia sudah dalam kondisi matang gonad (TKG III - V) sebesar66,91\%. Persentase terbesar adalah TKG IV sebesar 43,38\% diikuti TKG III (21,32\%) dan TKG V (2,21\%). Sedangkan cakalang yang belum matang gonad sebesar 33,09\%, yang terdiri dari TKG I $(16,91 \%)$ dan TKG II $(16,18 \%)$. Tingkat kematangan gonad ikan dipengaruhi oleh faktor internal dan faktor eksternal. Faktor internal antara lain spesies, umur dan ketersediaan hormon, sedangkan faktor eksternal antara lain suhu perairan dan jenis makanan (Effendie, 2002).

Dari analisis GSI dapat diketahui bahwa persentase GSI tertinggi terjadi pada bulan Oktober. Hal ini menunjukkan bahwa pada bulan setelahnya (November) terjadi pemijahan karena menurut Widodo (1986), dalam Mardijah dan Patria (2012), bahwa musim pemijahan terjadi kira-kira satu bulan setelah persentase tertinggi ikan yang matang gonad.Meskipun demikian, hal ini perlu dibuktikan lebih lanjut dengan melakukan penelitian selama satu tahun secara penuh tanpa terputus untuk mengetahui musim pemijahan cakalang di Samudera Hindia. Selain itu, waktu pemijahan ikan cakalang berlangsung dari bulan November hingga Desember yang dipengaruhi adanya perairan hangat (Froese \& Pauly, 2011).

Perhitungan ikan pertama kali matang gonad dengan metode Spearman - Karber (Udupa, 1986) diketahui bahwa ukuran pertama kali matang gonad cakalang di Samudera Hindia adalah 42,9 cm dengan kisaran antara 41,6 - 44,3 $\mathrm{cm}$. Hasil ini hampir sama dengan ukuran panjang pertama kali matang gonad $\left(L_{m}\right)$ cakalang yang tertangkap di Samudera Hindia Bagian Barat, tepatnya di perairan Mauritius yaitu $43 \mathrm{~cm}$ untuk betina dan $44 \mathrm{~cm}$ untuk jantan (Norungee \& Kawol, 2011). Indian Ocean Tuna Commission (IOTC) melaporkan bahwa ukuran panjang pertama kali matang gonad $\left(L_{m}\right)$ cakalang adalah $38 \mathrm{~cm}$, sedangkan dalam kondisi matang gonad secara penuh pada ukuran panjang $44 \mathrm{~cm}$ (Indian Ocean Tuna Commission, 2013).
Hasil dari penelitian ini lebih kecil dariukuran panjang pertama kali matang gonad $\left(L_{m}\right)$ cakalang yang tertangkap di Teluk Bone, Sulawesi Selatan yaitu $46,5 \mathrm{~cm}$ yang dicapai pada umur 6 bulan (Jamal, 2011). Meskipun demikian, hasil dari penelitian ini lebih besar daripadaukuran panjang pertama kali matang gonad $\left(L_{m}\right)$ cakalang yang tertangkap di Samudera Hindia Bagian Barat yaitu $37,8 \mathrm{~cm}$ (Grande $e t$ al., 2010). Perbedaan hasil tersebut dapat terjadi karena dalam spesies yang sama juga terdapat kemungkinan mengalami ukuran panjang pertama kali matang gonad yang berbeda (Udupa, 1986) yang sangat terkait dengan kesesuaian kondisi lingkungannya untuk pemijahannya (Lambert et al., 2003).

\section{KESIMPULAN}

Dari penelitian ini diketahui bahwa tingkat kematangan gonad (TKG) cakalang yang tertangkap didominasi oleh TKG IV sebesar $43 \%$ temuan ini menumjukan bahwa peluang pemijahan terjadi sepanjang tahun. Musim pemijahan cakalang di Samudera Hindia diperkirakan berlangsung mulai bulan November. Panjang pertama kali matang gonad $(\mathrm{Lm})$ cakalang adalah $42,9 \mathrm{~cm}$ dengan kisaran panjang cagak antara 41,6-44,3 cm.

\section{PERSANTUNAN}

Penelitian ini dibiayai dari DIPA Loka Penelitian Perikanan Tuna T.A 2012/2013. Penulis mengucapkan terima kasih kepada Ir. Retno Andamari, M.Sc. yang telah memberikan bimbingan selama proses analisis histologi.

\section{DAFTAR PUSTAKA}

Abidin, A. Z. 1986. The reproductive biology of tropical cyprinid from zoo lake. Kuala Lumpur, Malaysia. $J$. Fish. Biol. 29:381-392.

Alfonso-Dias, I., C. Reis \& P. Andrade. 2005. Reproductive aspects of Microchirus azevia (Risso, 1810) (Pisces: Soleidae) from the south coast of Portugal. Scientia Marina. 69(2): 275-283.

Andamari, R., J.H. Hutapea \& B.I. Prisantoso. 2012. Aspek reproduksi ikan tuna sirip kuning (Thunnus albacares). J.Ilmu.Tek.Kel.Tropis. 4 (1).89-96.

Collette, B.B. \& Nauen, C.E. 1983. FAO species catalogue.Vol. 2. Scombrids of the world. An annotated and illustrated catalogue of tunas, mackerels, bonitos and related species known to date. Food and Agriculture organization of the United Nations (FAO) Fisheries Synopsis number 125, volume 2.

Davis, T., J. Farley, M. Bravington \& R. Andamari. 1996. Final Report: Size at first maturity and recruitment into 
egg production of southern bluefin tuna. CSIRO Marine Research. 82 pp . (Unpublished).

Effendie, M.I. 2002. Biologi Perikanan. Penerbit Yayasan Pustaka Nusantara. Yogyakarta.163 pp.

Faizah, R. \& B. I. Prisantoso. 2010. Biologi reproduksi tuna mata besar (Thunnus obesus) yang tertangkap di Samudera Hindia. BAWAL Widya Riset Perikanan Tangkap. Pusat Penelitian Pengelolaan Perikanan dan Konservasi Sumberdaya Ikan..3(2): 129-137.

Froese, R. and Pauly D. (2011).FishBase: Katsuwonus pelamis.World Wide Web electronic publication. www.fishbase.org, version (12/2011).

FAO. 2012. Capture Production 1950-2010. Viewed 21 March 2012, [www.fao.org].

Grande, M., H. Murua, I. Zudaire \& M. Korta. 2010. Spawning activity and batch fecundity of skipjack, Katsuwonus pelamis, in the Western Indian Ocean. IOTC-2010-WPTT-47: 28 pp. (Unpublished).

Indian Ocean Tuna Commission. 2013. Report of the Fifteenth Session of the IOTC Working Party on Tropical Tunas. San Sebastian, Spain, 23-28 Oktober $2013.93 \mathrm{pp}$.

Jamal, M. 2011. Pemanfaatan Data Biologi Ikan Cakalang (Katsuwonus pelamis) dalam Rangka Pengelolaan
Perikanan Bertanggung Jawab di Perairan Teluk Bone. Jurnal Natur Indonesia. 14(1): 107-113.

Mardlijah, S. \& M.P. Patria. 2012. Biologi reproduksi ikan madidihang (Thunnus albacares Bonnatere 1788) di Teluk Tomini.J.Lit.Perikanan.Ind. Pusat Penelitian Pengelolaan Perikanan dan Konservasi Sumberdaya Ikan: 4 (1).27-34.

Matsumoto, W.M., R.A. Skillman \& A.E. Dizon. 1984. Synopsis of biological data on skipjack tuna, Katsuwonus pelamis. NOAA Tech.Rep.NMFS.Circ. 451:1-92.

Norungee, D. \& D. Kawol. 2011. Macroscopic study on some aspects of the reproductive biology of skipjack tuna (Katsuwonus pelamis) in the Western Indian Ocean.In: Proceeding Working Party on Tropical Tunas of the IOTC 2011.

Schaefer, K.M. 2001. Assessment of skipjack tuna (Katsuwonus pelamis) spawning activity in the eastern Pacific Ocean. Fish.Bull. 99.343-350.

Udupa, K.S. 1986. Statistical method of estimating the size at first maturity in fishes. ICLARM, Metro Manila, Fishbyte. 4 (2).8-10.

Widodo, J.W. 1986. Dynamics pool models and management of fisheries. Oseana XI.2: 36-47. 
Lampiran 1. Kriteria tingkat kematangan gonad Appendix 1. The criteria of gonad maturity stage

\begin{tabular}{|c|c|c|}
\hline $\begin{array}{c}\text { TKG / } \\
\text { Maturity stage }\end{array}$ & $\begin{array}{l}\text { Keadaan / } \\
\text { Condition }\end{array}$ & $\begin{array}{c}\text { Keterangan / } \\
\text { Remarks }\end{array}$ \\
\hline 1 & $\begin{array}{l}\text { Dara berkembang } \\
\text { (immature) }\end{array}$ & $\begin{array}{l}\text { Oosit kecil dengan sitoplasma berwarna ung u dengan } \\
\text { nukleus. Peripheral nulleoli (titik hitam kecil) dapat } \\
\text { dilihat di dalam nukleus yang mungkin menjadi tanda } \\
\text { munculnya kuning telur. }\end{array}$ \\
\hline 2 & $\begin{array}{l}\text { Perkembangan I } \\
\text { (early maturing) }\end{array}$ & $\begin{array}{l}\text { Kuning telur berwarna pucat ungu dimulai di sitoplasma. } \\
\text { Kuning telur berkonsentrasi di ping giran oosit dan } \\
\text { menyebar ke dalam ke arah nukleus. }\end{array}$ \\
\hline 3 & $\begin{array}{l}\text { Perkembangan II } \\
\text { (late maturing) }\end{array}$ & $\begin{array}{l}\text { Kuning telur berwarna merah muda terdapat di seluruh } \\
\text { oosit. Zona radiata luas, berubah warna menjadi } \\
\text { merah muda. Nukleus terletak di pusat. }\end{array}$ \\
\hline 4 & $\begin{array}{l}\text { Matang } \\
\text { (ripe) }\end{array}$ & $\begin{array}{l}\text { Nukleus berpindah ke pinggir oosit dan terkadang } \\
\text { dig anti dengan tetesan minyak. Terkadang dapat } \\
\text { terlihat butiran kuning telur melebur membentuk yolk } \\
\text { plates. }\end{array}$ \\
\hline 5 & $\begin{array}{l}\text { Salin } \\
\text { (spent) }\end{array}$ & $\begin{array}{l}\text { Kuning telur bergabung secara penuh berwarna merah } \\
\text { muda. Oosit membesar dan berbentuk tidak tera tur } \\
\text { (mungkin karena kehilangan cairan pada saat persiapan } \\
\text { analisis histologi). }\end{array}$ \\
\hline
\end{tabular}


Lampiran 2. Perhitungan ukuran panjang pertama kali matang gonad $(\mathrm{Lm})$ cakalang di Samudera Hindia Appendix 2. Calculations of length at first maturity $(\mathrm{Lm})$ of skipjack tuna in Indian Ocean

\begin{tabular}{|c|c|c|c|c|c|c|c|c|c|}
\hline $\begin{array}{c}\text { Kelas } \\
\text { Panjang } \\
\text { (cm) }\end{array}$ & $\begin{array}{c}\text { Tengah } \\
\text { Kelas } \\
\text { (cm) }\end{array}$ & $\begin{array}{c}\text { Log } \\
\text { Tengah } \\
\text { Kelas (Xi) }\end{array}$ & $\begin{array}{c}\text { Jumlah } \\
\text { Ikan (ni) }\end{array}$ & $\begin{array}{c}\text { Belum } \\
\text { Dewasa }\end{array}$ & $\begin{array}{c}\text { Dewas a } \\
\text { (ri) }\end{array}$ & $\begin{array}{c}\text { Proporsi } \\
\text { Dewasa } \\
\text { (pi) }\end{array}$ & $\begin{array}{c}\mathbf{X} \mathbf{i}+\mathbf{1}- \\
\mathbf{X} \mathbf{i}=\mathbf{X}\end{array}$ & $q i=1-p i$ & $\begin{array}{c}\text { (pixqi) } \\
\text { (ni-1) }\end{array}$ \\
\hline $34-36$ & 35 & 1.5441 & 1 & 1 & 0 & 0.000 & 0.0357 & 1.0000 & 0.0000 \\
\hline $37-39$ & 38 & 1.5798 & 6 & 6 & 0 & 0.000 & 0.0330 & 1.0000 & 0.0000 \\
\hline $40-42$ & 41 & 1.6128 & 13 & 11 & 2 & 0.154 & 0.0307 & 0.8462 & 0.0108 \\
\hline $43-45$ & 44 & 1.64 & 21 & 10 & 11 & 0.524 & 0.0286 & 0.4762 & 0.0125 \\
\hline $46-48$ & 47 & 1.6721 & 25 & 9 & 16 & 0.640 & 0.0269 & 0.3600 & 0.0096 \\
\hline $49-51$ & 50 & 1.6990 & 28 & 3 & 25 & 0.893 & 0.0253 & 0.1071 & 0.0035 \\
\hline $52-54$ & 53 & 1.7243 & 18 & 2 & 16 & 0.889 & 0.0239 & 0.1111 & 0.0058 \\
\hline $55-57$ & 56 & 1.7482 & 10 & 1 & 9 & 0.900 & 0.0227 & 0.1000 & 0.0100 \\
\hline $58-60$ & 59 & $1.7709 *)$ & 6 & 0 & 6 & 1.000 & 0.0215 & 0.0000 & 0.0000 \\
\hline $61-63$ & 62 & 1.7924 & 3 & 2 & 1 & 0.000 & 0.0205 & 1.0000 & 0.0000 \\
\hline $64-66$ & 65 & 1.8129 & 4 & 0 & 4 & 0.000 & 0.0196 & 1.0000 & 0.0000 \\
\hline \multirow[t]{2}{*}{$67-69$} & 68 & 1.8325 & 1 & 0 & 1 & 0.000 & 0.0000 & 1.0000 & 0.0000 \\
\hline & & & 136 & 45 & 91 & 4.9994 & & & 0.0523 \\
\hline
\end{tabular}

*) Last log size at which $100 \%$ fully mature

\begin{tabular}{ll}
\hline $\boldsymbol{m}=\boldsymbol{X} \boldsymbol{i}+\boldsymbol{X} / \mathbf{2}-(\boldsymbol{X} \boldsymbol{x} " \boldsymbol{p} \boldsymbol{i})$ & $\boldsymbol{C L}=\boldsymbol{A n t i l o g}\left(\left(\boldsymbol{m} \pm \mathbf{1 . 9 6} " \boldsymbol{X}^{\mathbf{2}} \boldsymbol{x} "(\boldsymbol{p} \boldsymbol{i} \boldsymbol{x} \boldsymbol{q} \boldsymbol{i}) /(\boldsymbol{n i}-\mathbf{1})\right)\right.$ \\
$\mathrm{m}=1.7709+(0.03 / 2)-(0.03 \times 4.99)$ & Upper limit: Antilog $\left(1.6328+1.96 "\left(0.03^{2} \times 0.052\right)=44.3\right.$ \\
\hline $\mathrm{m}=1.6328$ & Lower limit: Antilog $\left(1.6328-1.96 "\left(0.03^{2} \times 0.052\right)=41.6\right.$ \\
\hline Antilog $(1.6328)=42.9 \mathrm{~cm}$ & $\mathbf{L m}=\mathbf{4 2 . 9} \mathbf{c m}(\mathbf{4 1 . 6}-\mathbf{4 4 . 3} \mathbf{c m})$
\end{tabular}

